\title{
Comparison of Long-term Clinical Outcomes according to the Change in the Rectocele Depth between Transanal and Transvaginal Repairs for a Symptomatic Rectocele
}

\author{
Choon Sik Chung, Sang Hwa Yu, Jeong Eun Lee, Dong Keun Lee \\ Department of Surgery, Hansol Hospital, Seoul, Korea
}

Purpose: This study was aimed to compare the results of a transanal repair with those of a transvaginal levatorplasty and to determine the long-term clinical outcomes according to the change in the depth of the rectocele after the procedure. Methods: Of 50 women who underwent a rectocele repair from March 2005 to February 2007, 26 women (group A) received a transanal repair, and 24 (group B) received a transvaginal repair with or without levatorplasty. At 12 months after the procedures, 45 (group A/B, 22/23 women) among the 50 women completed physiologic studies, including anal manometry and defecography, and clinical-outcome measurements. The variations of the clinical outcomes with changes in the depth of the rectocele were also evaluated in 42 women (group A/B, 20/22) at the median follow-up of 50 months.

Results: On the defecographic findings, the postoperative depth of the rectocele decreased significantly in both groups (group A vs. B, $1.91 \pm 0.20$ vs. $2.25 \pm 0.46, \mathrm{P}=0.040$ ). At 12 months after surgery, 17 women in each group (group $\mathrm{A} / \mathrm{B}$, $77 / 75 \%$ ) reported improvement of their symptoms. However, only 11 and 13 women (group A/B, 55/59\%) of groups A and $\mathrm{B}$, respectively, maintained their improvement at the median follow-up of 50 months. Better results were reported in patients with a greater change in the depth of their rectocele $(\geq 4 \mathrm{~cm})$ after the procedure $(\mathrm{P}=0.001)$

Conclusion: In both procedures, clinical outcomes might become progressively worse as the length of the follow-up is increased.

\section{Keywords: Rectocele; Levator; Transanal; Transvaginal}

\section{INTRODUCTION}

A rectocele, an abnormal bulging of the anterior rectal wall and the posterior vaginal wall into the vaginal lumen, is frequently accompanied by a variety of complaints, such as a sense of incomplete evacuation, excessive strain, use of laxatives, and digital support

Received: April 21, 2012 • Accepted: June 26, 2012

Correspondence to: Choon Sik Chung, M.D.

Department of Surgery, Hansol Hospital, 445 Songpa-daero, Songpa-gu, Seoul 138-844, Korea

Tel: +82-2-413-6363(247), Fax: +82-2-413-8186

E-mail:drcschung@hanmail.net

Poster presentation at the ASCRS meeting, Vancouver, Canada, May 14 to 18, 2011.

(C) 2012 The Korean Society of Coloproctology

This is an open-access article distributed under the terms of the Creative Commons Attribution NonCommercial License (http://creativecommons.org/licenses/by-nc/3.0) which permits unrestricted noncommercial use, distribution, and reproduction in any medium, provided the original work is properly cited. during evacuation $[1,2]$. In clinical practice, however, the relationship between this anatomic deformity and clinical symptoms is not always clear. The exact pathogenesis of a rectocele is unclear, but it seems to be caused by fascial tears or detachment of the rectovaginal septum from the perineal body during labor; it may also be caused by chronic straining in patients with anismus $[1,3]$. The symptoms of a rectocele will be aggravated by repetitive increases in the intrarectal or the intraabdominal pressure after the formation of the rectocele. A symptomatic rectocele will require surgical intervention, for which a variety of operative methods can be used, with the expectation of permanent relief of the symptoms.

In the present study, we aimed retrospectively to compare the results of a transanal repair with those of a transvaginal levatorplasty. We also aimed to determine the long-term clinical outcomes according to the change in the depth of the rectocele after the procedure. 


\section{METHODS}

Of 50 women who underwent rectocele repair from March 2005 to February 2007, 26 women (group A: median age, 50 years old; range, 30 to 69 years) received a transanal repair (reinforcing by plication suture of the anterior rectal wall after mucosal excision overlying the rectocele), and 24 women (group B: median age, 50 years old; range, 26 to 71 years) received a posterior colporrhaphy (plication of the deficient rectovaginal septum with or without levatorplasty). The operation method was selected by the patient following a full explanation of the advantages and the disadvantages, such as dyspareunia after a transvaginal repair and anal incontinence after a transanal repair, between the two operative techniques. The study population was comprised of all patients operated on by one surgeon (CSC) at Hansol Hospital, Seoul, Korea.

Patients were selected for the operation based on clinical symptoms and physical examinations combined with defecographic findings (the depth of the rectocele $>4 \mathrm{~cm}$ ). Preoperative assessments included clinical interviews, colon transit studies, anal manometry, and defecography. At 12 months after the procedure, 45 (group A/B, 22/23 women) among the 50 women completed physiologic studies, including anal manometry and defecography, and clinical-outcome measurements. The change in the depth of the rectocele was assessed by using defecography performed preoperatively and postoperatively at 12 months. The depth of the rectocele was calculated during straining as the distance from the apex of the anterior rectal wall to a line drawn on the axis of the anal canal.

Clinical outcomes according to the change in the depth of the rectocele were evaluated in 42 women (group A/B, 20/22) by a nurse at the median follow-up of 50 months (range, 36 to 69 months). Subjective outcome was assessed by using the visual analogue scale (0 to 10) as excellent, good, moderate or poor according to the improvement of the symptoms. Excellent (7 to 10) indicated that the patient experienced complete improvement of the symptoms after surgery. Good (4 to 6) indicated that the patient experienced improvement, but was occasionally symptomatic. Moderate (1 to 3 ) indicated that the patient experienced minor improvement, but was frequently symptomatic. Poor (0) indicated that the patient did not experience of symptomatic improvement and even experienced a deterioration of the symptoms. Good and excellent were considered as desirable outcomes.

\section{Operative techniques}

Transanal repair

Under spinal anesthesia, the patient is placed in the prone jackknife position with the buttocks taped apart. After cleansing of the rectum with saline, rectal exposure is maintained with a Park's anal retractor. The submucosal plane is infiltrated with a 1:200,000 epinephrine solution. A rectal mucosal flap is raised using sharp dissection with electrocautery for the entire length of the rectocele from $1 \mathrm{~cm}$ above the dentate line. Interrupted sutures of 2-0 gly- colide/lactide copolymer (Polysorb, Covidien, Mansfield, MA, USA) are placed in a vertical or a horizontal stitch to plicate the rectal musculature. Redundant mucosa is then excised, and the mucosa is closed using the same suture material.

\section{Transvaginal repair}

Under spinal anesthesia with sedation, the patient is placed in the lithotomy position. A transverse skin incision, about 3 to $4 \mathrm{~cm}$, is made in the posterior vaginal wall in the introitus of the vagina. A sharp, blunt dissection with scissors and the index finger covered with gauze is performed to separate the posterior vaginal wall from the underlying rectovaginal septum. A midline incision is done along the length of the posterior vaginal wall to a site above the superior edge of the rectocele to enhance exposure. The dissection is carried laterally to the lateral vaginal sulcus and the medial margin of the puborectalis muscles. The rectovaginal fascia, with or without the underlying levator muscle, is plicated with interrupted sutures of 2-0 glycolide/lactide copolymer (Polysorb) while depressing the anterior rectal wall. Excess vaginal mucosa is trimmed and then re-approximated using the same suture material.

\section{Statistics}

Statistical analysis was performed using the IBM SPSS ver. 18.0 (IBM Co., Armonk, NY, USA). The Mann-Whitney U-test was used to compare the means of the variables for the groups. The paired t-test was used to compare subjective symptoms. Data were expressed as means \pm standard error (SE). Statistical significance was considered to be present when $\mathrm{P}<0.05$.

\section{RESULTS}

Both groups were comparable in terms of demographic and preoperative anal manometric findings (Table 1). According to the manometric study, in both groups, neither the mean anal resting pressure (group A, $61.50 \pm 21.98 \mathrm{mmHg}$ vs. $55.79 \pm 7.60 \mathrm{mmHg}$; group B, $56.22 \pm 14.44 \mathrm{mmHg}$ vs. $54.28 \pm 7.58 \mathrm{mmHg}$ ) nor the maximum squeezing pressure (group A, $126.67 \pm 31.10 \mathrm{mmHg}$ vs. $126.52 \pm 23.84 \mathrm{mmHg}$; group $\mathrm{B}, 126.63 \pm 23.54 \mathrm{mmHg}$ vs. $123.28 \pm$ $20.41 \mathrm{mmHg}$ ) was significantly changed after surgery. The depth of the rectocele showed a significantly decrease between pre- and postoperative defecographic findings in both groups (group A vs. $\mathrm{B}, 4.15 \pm 1.25 \mathrm{~cm}$ vs. $3.42 \pm 0.94 \mathrm{~cm}, \mathrm{P}=0.001$ vs. $\mathrm{P}=0.040$ ), and the size of the rectocele in group A was reduced more than it was in group $\mathrm{B}(\mathrm{P}=0.040)$ (Table 2$)$. At 12 months after surgery, 17 women in each group (group A/B, 77/75\%) reported improvement of their symptoms. However, only 11 and 13 women (group A/B, $55 / 59 \%$ ) of groups A and B, respectively, maintained their improvement at the median follow-up of 50 months (range, 36 to 69 months).

A correlation with long-term results was found in regard to changes in the depth of the rectocele, with better results being reported in patients with a greater change in the depth of their rec- 
Table 1. Demographic and clinical characteristics in both groups

\begin{tabular}{lccc}
\hline & Group A $(\mathrm{n}=26)$ & Group B $(\mathrm{n}=24)$ & P-value \\
\hline Age (yr), median (range) & $50(30-69)$ & $50(26-71)$ & 0.894 \\
Parity & $2.58 \pm 0.36$ & $2.46 \pm 0.29$ & 0.574 \\
Symptoms & & & $\mathrm{NS}$ \\
$\quad$ Incomplete evacuation & $21(80.8)$ & $21(87.5)$ & \\
$\quad$ Excessive strain & $19(73.1)$ & $19(79.2)$ & \\
Laxative use & $12(46.2)$ & $13(54.2)$ & \\
$\quad$ Digitations & $14(53.8)$ & $12(50.0)$ & \\
MARP (mmHg) & $61.50 \pm 21.98$ & $56.22 \pm 14.44$ & \\
MASP (mmHg) & $126.67 \pm 31.10$ & $126.63 \pm 23.54$ & \\
\hline
\end{tabular}

Values are presented as mean \pm SE or no. of patients (\%).

NS, not significant; MARP, mean anal resting pressure; MASP, mean anal squeezing pressure.

tocele $(\geq 4 \mathrm{~cm})$ after the procedure $(\mathrm{P}=0.001)$ (Table 3$)$. The mean operation times for groups $\mathrm{A}$ and $\mathrm{B}$ were $61.54 \pm 11.44$ minutes vs. $74.17 \pm 11.65$ minutes $(\mathrm{P}=0.014)$, respectively. The median length of hospital stay was two (range, 1 to 5 ) days in both groups. No operative complications, such as hematoma, wound disruption, or rectovaginal fistula, were noted in either group, but 3 patients developed dyspareunia in group $B$.

\section{DISCUSSION}

The underlying cause of a rectocele seems to be a weakening of the pelvic support structures and a thinning of the rectovaginal septum. The major risk factor for rectocele development is vaginal delivery, which may cause an injury to the pelvic floor muscle and nerve. Aging, pregnancy and high body mass index are also risk factors for its development, but it may occasionally occur in younger women or in those who have not delivered children $[4,5]$. In our study, three patients were nulliparous and less than 30 years old while the mean age and parity were similar in both groups.

A symptomatic rectocele results in obstructed defecation and constipation, but in clinical practice, the relationship between this anatomic abnormality and symptoms is not always clear. The indication for surgical repair of a rectocele still remains unclear. Conservative management, including biofeedback training and stool bulking agents, can be useful for patients with mild symptoms. If conservative treatment fails to relieve the symptoms, surgical treatment is advocated. Several types of surgical techniques, including transanal or transvaginal approaches, transperineal mesh repair, stapled transanal rectal resection (STARR) and laparoscopic assisted STARR, have been advocated for the management of a rectocele, but with varying success rates [6-11]. In our clinic, we prefer transanal or transvaginal repair for a symptomatic rectocele rather than STARR or transperineal mesh repair, transanal or transvaginal repair being a simpler and less expensive procedure with limited minor complications.
Table 2. Comparison of rectocele depth change between pre- and postoperative 12 months in both groups

\begin{tabular}{lccc}
\hline & Group A $(n=22)$ & Group B $(n=23)$ & P-value \\
\hline Depth of rectocele & & & \\
Preoperative & $5.36 \pm 0.90$ & $5.83 \pm 0.98$ & NS \\
Postoperative & $1.91 \pm 0.20$ & $2.25 \pm 0.46$ & 0.040 \\
Mean depth change & $4.15 \pm 1.25$ & $3.42 \pm 0.94$ & \\
P-value & 0.001 & 0.040 & \\
Operation time (min) & $61.54 \pm 11.44$ & $74.17 \pm 11.65$ & 0.014 \\
\hline
\end{tabular}

NS, not significant.

Table 3. Comparison of rectocele depth change between patients with improvement and no improvement at median follow up 50 months

\begin{tabular}{lccc}
\hline & $\begin{array}{c}\text { Improvement } \\
(\mathrm{n}=24)\end{array}$ & $\begin{array}{c}\text { No improvement } \\
(\mathrm{n}=18)\end{array}$ & P-value \\
\hline Depth of rectocele $(\mathrm{cm})$ & & & \\
$\quad$ Preoperative & $6.26 \pm 1.93$ & $5.78 \pm 0.93$ & \\
$\quad$ Postoperative & $2.10 \pm 0.20$ & $2.32 \pm 0.49$ & \\
Mean depth change & $4.15 \pm 1.25$ & $3.42 \pm 0.94$ & 0.001 \\
\hline
\end{tabular}

Few papers have assessed the surgical results prospectively by collecting physiological data to compare the transvaginal with the transanal rectocele repair $[12,13]$. Gynecologists traditionally adopt a vaginal approach, excising part of the posterior vaginal wall with or without an anterior levatorplasty. Transanal repair, mucosal resection and anterior rectal wall plication following submucosal dissection seems to be the procedure preferred by coloproctologists and has relatively high success rates, but this procedure has several disadvantages. First, access to a high rectocele may be limited. Second, there is a small risk of anal incontinence because both the resting and the squeeze pressures are reduced through the use of an anal dilator for adequate exposure $[12,14,15]$. Third, in cases of an enterocele with rectocele, the enterocele cannot be treated with a transanal approach. In our study, on manometric studies at 12 months postoperatively, transanal repair was not shown to adversely affect the anal resting pressure or the squeezing pressure.

STARR and transanal repair using a linear stapler are relatively new modalities with high success rates for rectocele repair $[7,16$, 17]. In spite of their relatively high success rates, a potential threat to structures located in front of the anterior rectal wall exists, and the overall cost related to the use of the stapler does seem to be prohibitive compared to the manual approach [18-20]. Petersen et al. [8] reported that the combination of STARR and laparoscopy provided the opportunity to perform a trananal rectal resection without the threat of intraabdominal organs caused by the enterocele.

Transvaginal repair consists of the plication of the levator muscle or the plication of the rectovaginal fascia to strengthen the rectovaginal septum or to close the specific defect of the rectovaginal 
fascia [21-23]. The tranvaginal approach is less likely to have an influence on the anal sphincter parameters (without compromising sphincter function) and allows the enterocele to be treated simultaneously. However, some studies have reported dyspareunia as a postoperative complaint in 19 to $41 \%$ of patients following posterior colporrhaphy, and this may be attributed to the use of levator muscle plication as part of the procedure $[9,22,24]$. At the 12-months follow-up, this study also showed new onset of dyspareunia in $18 \%$ of the patients ( 3 among 17 patients who still had a sexual life after surgery) who underwent a transvaginal repair, but no patients presented with dyspareunia at the median 50-month follow up. Altman et al. [25] reported that transvaginal rectocele repair using collagen mesh was not associated with an increased risk of dyspareunia, but that a substantial risk existed for recurrence with unsatisfactory anatomic and functional outcome one year after surgery. The concept of the rectocele as a defect in the integrity of the rectovaginal septum has been reported, but controversy still exists concerning the anatomical importance of the rectovaginal septum [4, 26-28]. The levator muscle is frequently too weak to approximate in the midline during levatorplasty, especially with elderly patients. In the current study, some patients in the transvaginal repair group had just a posterior colporrhaphy without levatorplasty due to not being able to identify the levator muscle in isolation.

Cochrane's review found that posterior vaginal repair showed a better result than transanal repair in term of recurrence [29]. Some papers have reported favorable results at short-term follow-up in about $80 \%$ of the patients, with that being significantly decreased to around $50 \%$ as the follow-up length is increased. In our study, both approaches appear to be safe and to have similar surgical results, but satisfaction with the surgical results decreases with time, with symptom improvement being noted in about $75 \%$ and $55 \%$ of the patients at the 12-month and the median 50-month followups after surgery. Several reasons exist for unsatisfying surgical result for rectoceles. First, knowing that an isolated rectocele is uncommon is important. It usually has a coexisting cause of constipation, such as internal rectal intussusceptions and paradoxical puborectalis contractions. Mellgren et al. [30] reported that $60 \%$ of patients with a rectocele, compared with $24 \%$ of those without rectocele, had paradoxical puborectalis contraction. In our study, we excluded patients with a rectocele combined with other pelvic floor diseases. Second, whether the anatomic deformity of the rectal wall in the rectocele is a cause or a result of constipation is uncertain. To prevent rectocele recurrence, patients who have had an anatomic correction for a rectocele need to take steps not to become constipated after surgery. In the current study, patients who had a greater change in the depth of the rectocele, as confirmed by defecography performed at one year after surgery, showed better long-term result. This finding suggests that a preoperatively larger rectocele may have better postoperative outcome. If patients who are not optimal for a surgical procedure to repair a rectocele are to be excluded and if surgical outcomes are to be improved, careful preoperative assessment, including preoperative counseling and anorectal physiologic studies, are vital [31].

In conclusion, regarding clinical and physiologic evaluation, this study showed that transanal repair for patients with an asymptomatic rectocele could provide long-term results compatible with those of a posterior colporrhaphy with or without levatorplasty and that a preoperatively larger rectocele might have a better postoperative outcome. Given the multiplicity of the pelvic floor and the evacuation dysfunction in patients presenting with a rectocele, long-term results indicated that the transanal and the transvaginal repairs for a rectocele had limited surgical outcomes. Multi-center trials are needed to provide an evidence base for determining which type of surgery is better in patients with an isolated clinical rectocele.

\section{CONFLICT OF INTEREST}

No potential conflict of interest relevant to this article was reported.

\section{REFERENCES}

1. Kahn MA, Stanton SL. Techniques of rectocele repair and their effects on bowel function. Int Urogynecol J Pelvic Floor Dysfunct 1998;9:37-47.

2. Pollak J, Davila GW. Rectocele repair: the gynecologic approach. Clin Colon Rectal Surg 2003;16:61-70.

3. Zbar AP, Lienemann A, Fritsch H, Beer-Gabel M, Pescatori M. Rectocele: pathogenesis and surgical management. Int J Colorectal Dis 2003;18:369-84.

4. Richardson AC. The rectovaginal septum revisited: its relationship to rectocele and its importance in rectocele repair. Clin Obstet Gynecol 1993;36:976-83.

5. Redding MD. The relaxed perineum and anorectal disease. Dis Colon Rectum 1965;8:279-82.

6. Mercer-Jones MA, Sprowson A, Varma JS. Outcome after transperineal mesh repair of rectocele: a case series. Dis Colon Rectum 2004;47:864-8.

7. Ayav A, Bresler L, Brunaud L, Boissel P. Long-term results of transanal repair of rectocele using linear stapler. Dis Colon Rectum 2004;47:889-94.

8. Petersen S, Hellmich G, Schuster A, Lehmann D, Albert W, Ludwig K. Stapled transanal rectal resection under laparoscopic surveillance for rectocele and concomitant enterocele. Dis Colon Rectum 2006;49:685-9.

9. Mellgren A, Anzen B, Nilsson BY, Johansson C, Dolk A, Gillgren P, et al. Results of rectocele repair: a prospective study. Dis Colon Rectum 1995;38:7-13.

10. Cundiff GW, Weidner AC, Visco AG, Addison WA, Bump RC. An anatomic and functional assessment of the discrete defect rectocele repair. Am J Obstet Gynecol 1998;179(6 Pt 1):1451-6.

11. Kenton K, Shott S, Brubaker L. Outcome after rectovaginal fascia reattachment for rectocele repair. Am J Obstet Gynecol 1999;181: 
1360-3.

12. van Dam JH, Huisman WM, Hop WC, Schouten WR. Fecal continence after rectocele repair: a prospective study. Int J Colorectal Dis 2000;15:54-7.

13. Boccasanta P, Venturi M, Calabro G, Trompetto M, Ganio E, Tessera G, et al. Which surgical approach for rectocele? A multicentric report from Italian coloproctologists. Tech Coloproctol 2001;5:149-56.

14. Nieminen K, Hiltunen KM, Laitinen J, Oksala J, Heinonen PK. Transanal or vaginal approach to rectocele repair: a prospective, randomized pilot study. Dis Colon Rectum 2004;47:1636-42.

15. Ho YH, Ang M, Nyam D, Tan M, Seow-Choen F. Transanal approach to rectocele repair may compromise anal sphincter pressures. Dis Colon Rectum 1998;41:354-8.

16. Longo A. Obstructed defecation because of rectal pathologies. novel surgical treatment: stapled transanal resection (STARR). In: Proceedings of the 14th Annual International Colorectal Disease Symposium; 2004 Feb 13-15; Ft Lauderdale, FL, USA.

17. Boccasanta P, Venturi M, Salamina G, Cesana BM, Bernasconi F, Roviaro G. New trends in the surgical treatment of outlet obstruction: clinical and functional results of two novel transanal stapled techniques from a randomised controlled trial. Int J Colorectal Dis 2004;19:359-69.

18. Aumann G, Petersen S, Pollack T, Hellmich G, Ludwig K. Severe intra-abdominal bleeding following stapled mucosectomy due to enterocele: report of a case. Tech Coloproctol 2004;8:41-3.

19. McDonald PJ, Bona R, Cohen CR. Rectovaginal fistula after stapled haemorrhoidopexy. Colorectal Dis 2004;6:64-5.

20. Boccasanta P, Venturi M, Stuto A, Bottini C, Caviglia A, Carriero A, et al. Stapled transanal rectal resection for outlet obstruction: a prospective, multicenter trial. Dis Colon Rectum 2004;47:1285-96.

21. Lamah M, Ho J, Leicester RJ. Results of anterior levatorplasty for rectocele. Colorectal Dis 2001;3:412-6.

22. Kahn MA, Stanton SL. Posterior colporrhaphy: its effects on bowel and sexual function. Br J Obstet Gynaecol 1997;104:82-6.

23. Abramov Y, Gandhi S, Goldberg RP, Botros SM, Kwon C, Sand PK. Site-specific rectocele repair compared with standard posterior colporrhaphy. Obstet Gynecol 2005;105:314-8.

24. van Dam JH, Hop WC, Schouten WR. Analysis of patients with poor outcome of rectocele repair. Dis Colon Rectum 2000;43: 1556-60.

25. Altman D, Zetterstrom J, Lopez A, Anzen B, Falconer C, Hjern F, et al. Functional and anatomic outcome after transvaginal rectocele repair using collagen mesh: a prospective study. Dis Colon Rectum 2005;48:1233-41.

26. DeLancey JO. Structural anatomy of the posterior pelvic compartment as it relates to rectocele. Am J Obstet Gynecol 1999;180: 815-23.

27. Aigner F, Zbar AP, Ludwikowski B, Kreczy A, Kovacs P, Fritsch H. The rectogenital septum: morphology, function, and clinical relevance. Dis Colon Rectum 2004;47:131-40.

28. Leffler KS, Thompson JR, Cundiff GW, Buller JL, Burrows LJ, Schon Ybarra MA. Attachment of the rectovaginal septum to the pelvic sidewall. Am J Obstet Gynecol 2001;185:41-3.

29. Maher C, Baessler K, Glazener CM, Adams EJ, Hagen S. Surgical management of pelvic organ prolapse in women. Cochrane Database Syst Rev 2007;(3):CD004014.

30. Mellgren A, Lopez A, Schultz I, Anzen B. Rectocele is associated with paradoxical anal sphincter reaction. Int J Colorectal Dis 1998;13:13-6.

31. Hirst GR, Hughes RJ, Morgan AR, Carr ND, Patel B, Beynon J. The role of rectocele repair in targeted patients with obstructed defaecation. Colorectal Dis 2005;7:159-63. 